\title{
Correction to: New insights into the trophic ecology of the scalloped hammerhead shark, Sphyrna lewini, in the eastern tropical Pacific Ocean
}

\author{
Colombo Estupiñán-Montaño (1) \\ Elena Tamburin (1) Antonio Delgado-Huertas
}

Published online: 1 December 2021

(C) Springer Nature B.V. 2021

\section{Correction to: Environ Biol Fish https://doi.org/10.1007/s10641-021-01187-4}

The original version of this published article contained an error in the third formula (p. 4). The formula used to estimate the age in this study was published as:

$t=-\frac{\ln \ln \left(1-\frac{L_{t}}{L_{\infty}}\right)}{K}+t_{0}$

However, the formula contained two " $l n$ " components in error. The correct formula to estimate the age has only one "In" component. The corrected formula should be presented as:

$t=-\frac{\ln \left(1-\frac{L_{t}}{L_{\infty}}\right)}{K}+t_{0}$

Publisher's note Springer Nature remains neutral with regard to jurisdictional claims in published maps and institutional affiliations.

The original article can be found online at https://doi.org/ 10.1007/s10641-021-01187-4.

C. Estupiñán-Montaño $(\bowtie) \cdot$ E. Tamburin Fundación Alium Pacific, Carrera 26 No. 5C-13,

Santiago de Cali, Colombia

e-mail: goliathcem@gmail.com

A. Delgado-Huertas Instituto Andaluz de Ciencias de la Tierra (CSIC-UGR), Armilla, Granada, Spain 